\title{
Comparison of Bioelectrical Impedance Analysis and Air Displacement Plethysmography
}

\author{
Comparación de Análisis de Impedancia Bioeléctrica y Pletismografía de Desplazamiento de Aire
}

\author{
Klára Coufalová1; Martin Komarc ${ }^{1}$ \& Darryl James Cochrane ${ }^{2}$
}

COUFALOVÁ, K.; KOMARC, M. \& COCHRANE, D. J. Comparison of bioelectrical impedance analysis and air displacement plethysmography. Int. J. Morphol., 37(3):985-990, 2019.

SUMMARY: The measurement of body composition has become an important component in the diagnosis of health, physical conditioning and nutritional status. The aim of this study was to compare two methods of detecting body composition, bioelectrical impedance and air displacement plethysmography for athletes and non-athletes. Specifically, we compared the parameters as fat mass, fat free mass and the value of basal metabolic rate. A sample size of 52 men (age 26.2 \pm 5.4 years) that included a group of mixed martial arts (MMA) fighters $(n=31$, age $27.2 \pm 5.5$ years $)$ and a group of the non-athletes $(n=21$, age $24.6 \pm 5.1$ years $)$. Both groups were measured by bioelectrical impedance and air displacement plethysmography. Significant differences in \% body fat $(\mathrm{p}<0.05)$ and fat-free mass $(\mathrm{p}<0.05)$ were noted between bioelectrical impedance and air displacement plethysmography of non-athletes, but there were no significant differences for athletes. Furthermore, there was a significant difference $(p<0.001)$ of basal metabolic rate between bioelectrical impedance and air displacement plethysmography, but the correlation with fat free mass was very strong for both methods. Therefore, the use of bioelectrical impedance and air displacement plethysmography may be useful for detecting changes in body composition, but their accuracy is controversial and for this reason we recommend using only one method and not combining them.

KEY WORDS: Body composition; Bioelectrical impedance; Plethysmography; Body fat; Basal metabolic rate.

\section{INTRODUCTION}

The study of modern human body composition is over 100 years old, spanning several disciplines such as clinical nutrition, sport and exercise science, and medicine (Heymsfield et al., 2005). Currently, there are various methods of measuring body fat, fat free mass or other parameters of body composition, which vary in accuracy, ease of measurement, cost and equipment requirements. The most common method of body composition analysis is bioelectrical impedance, which is relatively inexpensive, highly portable, non-invasive and easy to use. Bioelectrical impedance (BIA) is based on measurement of the resistance of body tissues to the flow of a small electrical signal. Since adipose tissue is a poor electrical conductor due to its small water content, larger impedance values are observed for individuals with higher levels of body fat (Heyward \& Wagner, 2004). Currently, there are several different types of BIA analysers such as, segmental, leg-to-leg, and hand-to-hand (Weaver et al., 2009) BIA has its limitations, where the amount of water in the body may influence the electrical resistance leading to an inaccurate reading (de Fijter et al., 1993; Oppliger $\&$ Bartok, 2002). In general, the typical prediction error of the traditional BIA method has been reported in the range of 3-4 $\%$ body fat (BF) (Heyward \& Wagner).

Another type of body composition analysis is airdisplacement plethysmography (ADP). Currently, there is only one commercial available system known as BOD POD (Life Measurement Inc, Concord, CA, USA). This method determines body density by measuring body volume by air displacement and body weight. Body weight is measured using scales and body volume is initially measured by the volume of the chamber while vacant followed by when the participant is inside the chamber. By subtraction, the volume of the participant is determined. Once body volume and weight are determined, body density can be computed from an equation to provide \% $\mathrm{BF}$. Body volume is determined by monitoring changes in pressure within a closed chamber. These pressure changes are achieved by oscillating a speaker mounted between the front testing chamber and a rear reference chamber, which causes complementary pressure changes in each chamber. The pressure changes are very small and are 
undetected by the participant. The manufacturer states that the general error range of the BOD POD is 1-2\% (Dempster $\&$ Aitkens, 1995). The majority of ADP validation studies have compared \% BF estimates from ADP to those of hydrostatic weighting (HW), dual x-rays absorptiometry (DEXA), or both. Fields et al. (2002) reviewed 15 studies and reported that for adults the difference between means ranged from $-4.0 \%$ to $1.9 \% \mathrm{BF}(\mathrm{ADP}-\mathrm{HW}$ ) and -3.0 to 1.7 $\% \mathrm{BF}$ (ADP-DEXA). The average mean difference in $\% \mathrm{BF}$ between ADP and HW or DEXA was calculated to be less than $1.0 \% \mathrm{BF}$. The authors concluded that on average the methods agreed well, but there were large variations (Fields et al.; Weaver et al.).

Currently, the BIA instrument is designed as a commercial device that measures body fat percentage by different formulated software and extra regression equations for parameters such as weight, height, age and sport activity (Sivapathy et al., 2013). The problem of BIA prediction equations is well-known. If the prediction equation is not prescribed correctly the accuracy of results is often very low. Some errors we can eliminate by accurate measurement of body height and weight but the distinction of athletes and non-athletes could be problematic. Manufactures have stated that an athlete is classified that has a minimum of 12 hours of training per week with a resting heart rate that is less than 60 $\mathrm{bpm}$. As a comparison method the selection of the ADP is appealing because it is non-invasive, relatively fast and easy to use. In the past, the ability of ADP to estimate \% BF has been validated against several criterion methods including DXA, which has indicated an excellent correlation of 0.890.91 (Ballard et al., 2004; Bentzur et al., 2008).

Knowledge of basal metabolic rate is important for determination of energy expenditure. An optimal balance between energy intake and energy expenditure is crucial for athlete performance. If the energy expenditure is higher than energy intake this lack of energy can lead to reduction of muscle mass, longer recovery, fatigue, higher risk of injury or illness. Less energy expenditure than energy intake results in a positive energy balance and storage of energy primarily as body fat, which may be detrimental especially for endurance and aesthetic sports, or sports with weight categories. Typically, some athletes want to acquire knowledge of their basal metabolic rate and from this parameter along with their physical activity they can estimate their optimal energy intake. This is pertinent for athletes from combat sports especially if they are trying to reduce body mass in the quest to making a certain weight category where measuring their basal metabolism rate may assist them to regulate their energy intake. Therefore, many combat athletes may find it beneficial to know their basal metabolic rate, however the problem is that the measurement is very difficult to undertake.
The gold standard to determine the resting energy expenditure is measured by indirect calorimetry, but this method is expensive and requires equipment and trained personnel to guarantee the reliability (ten Haaf T \& Weijs, 2014). Therefore, body composition devices or predictive equations are often used to estimate the basal metabolic rate. The predictive equations include age, sex, body height and body weight but do not include active mass, therefore they may not suitable for athletes. Basal metabolic rate is primarily dependent on the fat-free mass, however there is no knowledge on the correlation between basal metabolic rate and fat-free mass.

Weight categories are used in a variety of sports, especially combat sports (boxing, wrestling, mixed martial arts) to promote fair competition by matching opponents of equal stature and body mass; where athletes aim to compete at the lightest body mass possible in the expectation that it will provide an advantage over opponents (Langan-Evans et al., 2011). Consequently, athletes monitor their body mass and composition at regular intervals with the goal of having a high level of muscle mass and low level of fat mass, which contrasts to that of nonathletes. However, within adults there is little research to determine if there are any differences between athletes and nonathletes. Therefore, the primary aim of this study was to compare fat mass (FM) and fat-free mass (FFM) of BIA and ADP within groups of athletes and non-athletes. Further we were interested in measurement of basal metabolic rate (BMR). This parameter is important for energy expenditure estimation. Nowadays we usually use equations for BMR which are not suitable for athletes and also for obese people with the lack of muscle mass. A secondary aim of this study was to compare basal metabolic rate from BIA and ADP. We hypothesize that comparing BIA and ADP there would be no significant difference in measures of body fat, fat-free mass and basal metabolic rate and that a strong correlation would exist between fat-free mass and basal metabolic rate.

\section{MATERIAL AND METHOD}

Total 31 mixed martial arts (MMA) fighters (age $27.2 \pm 5.5$ years) and 21 non-athletes (age $24.6 \pm 5.1$ years) volunteered to participate in this study and gave their written consent where ethical approval was granted by the University Human Ethics. All athletes were involved in MMA for at least 1 year and completed at least 1 competition. The criteria for using the BIA equation for athletes, were that MMA fighters to be 18 years or older, resting heart rate no greater than 60 bpm and were involved in physical activity of a minimum of 12 hours per week. All procedures were cleared by local ethics committee and informed consent was signed by all participants. All measurements were conducted according to the Declaration 
of Helsinki for human studies of the World Medical Association.

Participants were asked to abstain from eating or drinking for two hours as well as to refrain from moderate or vigorous exercise for 24 hours before measurement. All testing was performed in tight-fitting underwear with no shirt. The order of testing was all participants completed body height first followed by BIA and then ADP.

Bioelectrical impedance was measured using the octopolar TANITA MC-980 MA (Tanita Europe) using 1, 5, 50, 250,500 and $1000 \mathrm{kHz}$. The participant's age, gender and height were entered into the device. This type of bioelectrical impedance analyser offers two equations which are categorised as 'normal' or 'athlete'. For the group of non-athletes the 'normal' equation was used and for MMA fighters the 'athlete' equation was used.

The $\%$ BF of all participants was determined with the Siri formula (Biaggi et al., 1999; Claros et al., 2005) using body density values estimated by BOD POD (Life Measurement Inc, Concord, CA, USA). For the BOD POD measurements, predicted lung volume was used in the protocol. The lung volume was not measured using the procedure available with the BOD POD device, as this would introduce an additional source of error. Therefore, before the commencement of each test the BOD POD was calibrated according to the manufacturer's instructions using a cylinder of known volume (50.127 1). With the participant wearing a lycra cap were weighed on an electronic scale and then entered the chamber. Two measurements of body volume were taken each lasting approximately 50 seconds. If these two body volumes differed by more than $150 \mathrm{ml}$, a third body volume measurement was performed.
Statistical Analyses. Basic descriptive statistics (mean, standard deviation, skewness, kurtosis) were calculated for all of the variables, which were subsequently tested for normality using Kolmogorov-Smirnov test. Differences in participant characteristics (age, height, body weight, BMI) between athletes and non-athletes were evaluated by the independent-group t-test. Body composition measured by bioelectrical impedance and air displacement plethysmography in the two groups was assessed by 2-way repeated ANOVA (method $x$ group), followed by the LSD post-hoc comparisons. Pearson correlation coefficient was used to express the magnitude of association between bioelectrical impedance and air displacement plethysmography measurements. P-values < 0.05 were considered to be statistically significant. Statistical analyses were performed using SPSS version 23 (SPSS Inc., Chicago, IL, USA).

\section{RESULTS}

Athletes (MMA fighters, $n=31$ ) and non-athletes $(n=21)$ did not differ significantly $(\mathrm{p}>0.05)$ in physical characteristics of age, height, weight, BMI (Table I).

In the group of non-athletes the $\% \mathrm{BF}$ was significantly lower $(\mathrm{p}=0.017)$ in ADP $(12.4 \pm 7.1 \%)$ compared to BIA $(14.3 \pm 5.3 \%)$. In contrast, ADP had slightly higher values of \% BF than BIA in MMA athletes, however, the difference was not statistically significant (ADP $=9.6 \pm 3.5 ; \mathrm{BIA}=9.0 \pm 3.8 ; \mathrm{p}=0.357)$. The differences in $\% \mathrm{BF}, \mathrm{FFM}$ and $\mathrm{BMR}$ or RMR for BIA versus ADP are summarised in Table II.

Table I. Physical characteristics of athletes and non-athletes (mean \pm SD).

\begin{tabular}{lccccc}
\hline & \multicolumn{2}{c}{ Non-athletes $(\mathrm{n}=21)$} & \multicolumn{2}{c}{ MMA athletes $(\mathrm{n}=31)$} & \\
& mean $\pm \mathrm{SD}$ & range & mean $\pm \mathrm{SD}$ & range & $\mathrm{p}$ \\
\hline Age $(\mathrm{yrs})$ & $24.6 \pm 5.1$ & $20-40$ & $27.2 \pm 5.5$ & $19-37$ & 0.084 \\
Height $(\mathrm{cm})$ & $179.5 \pm 5.7$ & $166.5-188.0$ & $180.0 \pm 7.3$ & $165.0-193.8$ & 0.844 \\
Weight $(\mathrm{kg})$ & $78.7 \pm 9.6$ & $63.9-100.0$ & $81.1 \pm 10.3$ & $60.6-108.6$ & 0.389 \\
BMI $\left(\mathrm{kg} / \mathrm{m}^{2}\right)$ & $24.4 \pm 2.7$ & $20.7-29.5$ & $25.0 \pm 2.3$ & $21.3-30.8$ & 0.384 \\
\hline
\end{tabular}

Table II. Comparison of percentage body fat ( \% BF), fat-free mass (FFM) and basal metabolic rate $(\mathrm{BMR})$ and resting metabolic rate (RMR) between BIA and ADP (mean \pm SD).

\begin{tabular}{lccccc}
\hline & \multicolumn{3}{c}{ Non-athletes $(\mathrm{n}=21)$} & \multicolumn{3}{c}{ MMA athletes $(\mathrm{n}=31)$} & \\
\hline & mean $\pm \mathrm{SD}$ & $\mathrm{p}^{\mathrm{w}}$ & mean $\pm \mathrm{SD}$ & $\mathrm{p}^{\mathrm{w}}$ & $\mathrm{pb}^{\mathrm{b}}$ \\
\hline \%BF (BIA) & $14.3 \pm 5.28$ & 0.017 & $9.0 \pm 3.8$ & 0.357 & $<0.001$ \\
\%BF (ADP) & $12.4 \pm 7.1$ & & $9.6 \pm 3.5$ & & 0.040 \\
FFM (BIA) (kg) & $67.1 \pm 6.37$ & 0.045 & $73.6 \pm 7.5$ & 0.280 & 0.002 \\
FFM (ADP) (kg) & $68.4 \pm 6.0$ & & $73.0 \pm 7.6$ & & 0.024 \\
BMR (BIA) (kJ) & $8281.8 \pm 802.6$ & $<0.001$ & $8994.5 \pm 989.1$ & $<0.001$ & 0.005 \\
RMR (ADP) (kJ) & $7560.5 \pm 665.5$ & & $8017.7 \pm 860.9$ & & 0.064 \\
\hline
\end{tabular}

Note: pw: within-group differences between BIA and ADP measurement; pb: between-group differences between Non-athletes and MMA athletes 
Table III shows correlations between \% BF, FFM and RMR with FFM. The \% BF correlation between BIA and ADP was $r=0.830$ and $r=0.638$ (both $p<0.001$ ) for nonathletes and athletes respectively. We also found a significant correlation between FFM between BIA and ADP $(r=0.864$, resp. $r=0.940, p<0.001)$. The results of BMR RMR from both methods were significantly correlated with FFM (see Table III).

Table III. Correlations between selected parameters.

\begin{tabular}{lcc}
\hline & $\begin{array}{c}\text { Non-athletes } \\
(\mathrm{n}=21)\end{array}$ & $\begin{array}{c}\text { MMA athletes } \\
(\mathrm{n}=31)\end{array}$ \\
\hline \% BF (BIA) with \% BF (ADP) & 0.830 & 0.638 \\
FFM (kg) (BIA) with FFM (kg) (ADP) & 0.864 & 0.940 \\
BMR (BIA) (kJ) with FFM (kg) (BIA) & 0.995 & 0.995 \\
RMR (ADP) (kJ) with FFM (kg) (ADP) & 0.984 & 0.998 \\
\hline
\end{tabular}

All correlations are significant with $p<0.001$.

\section{DISCUSSION}

The main finding of this study reported that for nonathletes a significant difference in $\%$ body fat (p?0.05) and fat-free mass $(p<0.05)$ existed between BIA and ADP. There was no significant difference in $\%$ body fat and fat-free mass for athletes but BIA overestimated \% BF (1.9\%) and FFM was lower than ADP (1.3 kg) compared to BIA. In contrast, previous research comparing BIA and ADP (Sivapathy et al.) reported non-significant difference in body fat mass between male athletes and non-athletes. Similarly, an earlier study of ninety-nine healthy participants ( 52 females and 47 males, aged $38 \pm 14$ years) found no significant difference between BIA (InBody 3.0) and ADP (BOD POD) (Malavolti et al., 2007). Although our results of non-athletes were significantly different, total difference in $\%$ body fat was only $1.9 \%$ and in fat-free mass $1.3 \mathrm{~kg}$.

From the current results the estimate of percent body fat from BIA and ADP was very high ( $\% \mathrm{BF}$ of non-athletes: $r=0.830$; FFM of non-athletes: $r=0.864$; FFM of athletes: $r=0.940$ ), which is supported by other studies that have reported similar correlation of 0.859-0.900 (Biaggi et al.; Levenhagen et al., 1999; Johnson et al., 2012; Reinert et al., 2012). The current correlation of the athletes' \% BF was lower $(r=0.638)$, due to the relative homogeneity of athletes (i.e. all athletes had a low level of body fat). Despite a strong correlation $(\mathrm{r}=0.850)$ between a hand-to-hand BIA analyser and ADP, Weaver et al. reported BIA underestimated \% BF $(1.4 \pm 4.3 \%)$, however when gender was taken into account a significant difference was only observed in females. Recently, Hillier et al. (2014) reported a strong within- and between-day relationship for $\% \mathrm{BF}$ from ADP and BIA devices; additionally, the two methods had a high correlation but the mean difference between the two methods was $3.1 \%$.
In assessing fat free mass, DEXA is regarded as the most accurate $(1.5 \%)$ and precise (1-4\%) compared to other body composition methods of ADP, HW and BIA (Ellis, 2001). ADP and HW is reported to have a precision and accuracy of 1-2\% and 2-3\% respectively, with BIA having the lowest precision (2-4\%) and accuracy (2-8\%) of the four methods analyzed (Ellis). Furthermore, DEXA had the lowest amount of detectable change $(1.5 \mathrm{~kg})$ compared to ADP (2 kg), HW (2 kg) and BIA (4 kg) [20]. In a recent study the validity and reliability of $\%$ BF from BIA, ADP and DEXA was assessed (von Hurst et al., 2016) where BIA demonstrated excellent relative agreement to the estimated true value, but wide limits of agreement with BIA underestimated $\%$ BF by $2 \%$. All three methods (BIA, ADP and DXA) showed excellent reliability with repeat measurements varied by less than $0.2 \%$.

The current results show a very strong positive correlation between basal metabolic rate, respectively resting metabolic rate and fat-free mass. For BIA the correlation was $r=0.995$ for both non-athletes and athletes and for ADP $\mathrm{r}=0.984$ and 0.998 for non-athletes and athletes, respectively. This indicates that both methods determine BMR or RMR depending on fat-free mass. This would suggest that both methods are more accurate than equations, which use only basic characteristics such as gender, age, height and weight. For this reason we also wanted to compare BIA and ADP for BMR. We found a significant difference between BIA and ADP $(p<0.001)$, which indicates that the basal metabolic rate from BIA was higher than resting metabolic rate from ADP. The average value of this parameter for non-athletes was $721.3 \mathrm{~kJ}$ higher for BIA, for athletes $976.8 \mathrm{~kJ}$. Our assumption that basal metabolic rate would be higher in athletes is due to their relatively high fat free mass, which has been confirmed in both BIA and ADP. Park 
\& Park (2015) investigated a relationship between bioelectrical impedance-derived estimates of basal metabolic rate and body composition parameters in female Korean college students. They used BIA device InBody 720 and found significant positive correlation with all parameters of body composition. Unfortunately, a comparison cannot be made as no study has focused on validating resting metabolic rate by ADP. Finally, the BMR values measured by BIA for non-athletes and athletes are approximately $8.7 \%$ and 10.9 $\%$ and higher respectively compared to ADP. Therefore, to better assess basal metabolic rate, further research is required to compare the present results with gas analysis via direct or indirect calorimetry.

\section{CONCLUSION}

We found significant differences in $\%$ body fat and fat-free mass of non-athletes between bioelectrical impedance and air displacement plethysmography. According to our results BIA slightly overestimates \% BF of non-athletes. Surprisingly we did not find any significant differences in \% BF and FFM of athletes. Although our results of non-athletes were significantly different, total difference in $\%$ body fat was only $1.9 \%$ and in fat-free mass $1.3 \mathrm{~kg}$. We hypothesized that BMR will reflect the amount of fat-free mass. This assumption was confirmed for both methods (BIA and ADP). However, there was a significant difference of BMR between BIA and ADP. The results of BMR measured by BIA were higher than by ADP. To determine the accuracy of these methods, a comparison with calorimetry would be appropriate. Therefore, the use of BIA and ADP may be appropriate for detecting body composition changes, but its accuracy is questionable and for this reason we recommend that only one method is used.

FUNDING. This work was supported by Programme for the Development of Fields of Study at Charles University under Grant Q41 and Charles University Centre of Excellence project (UNCE/HUM/032).

COUFALOVÁ, K.; KOMARC, M. \& COCHRANE, D. J. Comparación de análisis de impedancia bioeléctrica y pletismografía de desplazamiento de aire. Int. J. Morphol., 37(3):985-990, 2019.

RESUMEN: La medición de la composición corporal se ha convertido en un componente importante en el diagnóstico de la salud, el acondicionamiento físico y el estado nutricional. El objetivo de este estudio fue comparar dos métodos para detectar la composición corporal, la impedancia bioeléctrica y la pletismografía de desplazamiento de aire para atletas y no atle- tas. Específicamente, comparamos los parámetros como masa grasa, masa libre de grasa y el valor de la tasa metabólica basal. Un tamaño de muestra de 52 hombres (edad 26,2 \pm 5,4 años) de un grupo de luchadores de artes marciales mixtas (MMA) ( $\mathrm{n}=$ 31 , edad 27,2 $\pm 5,5$ años) y un grupo de no deportistas $(\mathrm{n}=21$, edad 24,6 $\pm 5,1$ años). Ambos grupos se midieron por impedancia bioeléctrica y pletismografía de desplazamiento de aire. Se observaron diferencias significativas en el porcentaje de grasa corporal $(\mathrm{p}<0,05)$ y la masa libre de grasa $(\mathrm{p}<0,05)$ entre la impedancia bioeléctrica y la pletismografía de desplazamiento de aire de los no deportistas, sin embargo no hubo diferencias significativas en los atletas. Además, se observó una diferencia significativa $(\mathrm{p}<0,001)$ de la tasa metabólica basal entre la impedancia bioeléctrica y la pletismografía de desplazamiento de aire, pero la correlación con la masa libre de grasa fue importante para ambos métodos. Por lo tanto, el uso de la pletismografía de impedancia bioeléctrica y desplazamiento de aire puede ser útil para detectar cambios en la composición corporal, pero su precisión es controvertida por lo que recomendamos usar solo un método y no una combinación de ambos.

PALABRAS CLAVE: Composición corporal; Impedancia bioeléctrica; Pletismografía; Grasa corporal; Tasa metabólica basal

\section{REFERENCES}

Ballard, T. P.; Fafara, L. \& Vukovich, M. D. Comparison of Bod Pod and DXA in female collegiate athletes. Med. Sci. Sports Exerc., 36(4):731$5,2004$.

Bentzur, K. M.; Kravitz, L. \& Lockner, D. W. Evaluation of the BOD POD for estimating percent body fat in collegiate track and field female athletes: a comparison of four methods. J. Strength Cond. Res., 22(6):1985-91, 2008.

Biaggi, R. R.; Vollman, M. W.; Nies, M. A.; Brener, C. E.; Flakoll, P. J.; Levenhagen, D. K.; Sun, M.; Karabulut, Z. \& Chen, K. Y. Comparison of air-displacement plethysmography with hydrostatic weighing and bioelectrical impedance analysis for the assessment of body composition in healthy adults. Am. J. Clin. Nutr., 69(5):898-903, 1999.

Claros, G.; Hull, H. R. \& Fields, D. A. Comparison of air displacement plethysmography to hydrostatic weighing for estimating total body density in children. B. M. C. Pediatr., 5:37, 2005.

de Fijter, C. W.; de Fijter, M. M.; Oe, L. P.; Donker, A. J. \& de Vries, P. M. The impact of hydration status on the assessment of lean body mass by body electrical impedance in dialysis patients. Adv. Perit. Dial., 9:1014, 1993.

Dempster, P. \& Aitkens, S. A new air displacement method for the determination of human body composition. Med. Sci. Sports Exerc., 27(12):1692-7, 1995.

Ellis, K. J. Selected body composition methods can be used in field studies. J. Nutr., 131(5):1589S-95S, 2001.

Fields, D. A.; Goran, M. I. \& McCrory, M. A. Body-composition assessment via air-displacement plethysmography in adults and children: a review. Am. J. Clin. Nutr., 75(3):453-67, 2002.

Heymsfield, S. B.; Lohman, T. G.; Wang, Z. \& Going, S. B. (Eds.). Human Body Composition. $2^{\text {nd }}$ ed. Champaign (IL), Human Kinetics Publishers, 2005.

Heyward, V. H. \& Wagner, D. R. Applied Body Composition Assessment. Champaign (IL), Human Kinetics Publishers, 2004. pp.21, 87-98. 
Hillier, S. E.; Beck, L.; Petropoulou, A. \& Clegg, M. E. A comparison of body composition measurement techniques. J. Hum. Nutr. Diet., 27(6):626-31, 2014

Johnson, K. E.; Naccarato, I. A.; Corder, M. A. \& Repovich, W. E. Validation of three body composition techniques with a comparison of ultrasound abdominal fat depths against an octopolar bioelectrical impedance device. Int. J. Exerc. Sci., 5(3):205-13, 2012.

Langan-Evans, C.; Close, G. L. \& Morton, J. P. Making weight in combat sports. Strength Cond. J., 33(6):25-39, 2011.

Levenhagen, D. K.; Borel, M. J.; Welch, D. C.; Piasecki, J. H.; Piasecki, D. P.; Chen, K. Y. \& Flakoll, P. J. A comparison of air displacement plethysmography with three other techniques to determine body fat in healthy adults. J. P. E. N. J. Parenter. Enteral Nutr., 23(5):293-9, 1999.

Malavolti, M.; Pietrobelli, A.; Dugong, M.; Poli, M.; Romagnoli, E.; De Cristofaro, P. \& Battistini, N. C. A new device for measuring resting energy expenditure (REE) in healthy subjects. Nutr. Metab. Cardiovasc. Dis., 17(5):338-43, 2007.

Oppliger, R. A. \& Bartok, C. Hydration testing of athletes. Sports Med., 32(15):959-71, 2002.

Park, J. \& Park, J. H. Relationship between bioelectrical impedance-derived estimates of basal metabolic rate and body composition parameters in female Korean college students. S. Afr. J. Res. Sport Phys. Educ. Recreat., 37(1):87-98, 2015.

Reinert, B. L.; Pohlman, R. \& Hartzler, L. Correlation of air displacement plethysmography with alternative body fat measurement techniques in men and women. Int. J. Exerc. Sci., 5(4):367-78, 2012.

Sivapathy, S.; Chang, C. Y.; Chai, W. J.; Ang, Y. K. \& Yim, H. S. Assessment of hydration status and body composition of athlete and non-athlete subjects using bioelectrical impedance analysis. J. Phys. Educ. Sport, 13(2):157-62, 2013.

ten Haaf, T. \& Weijs, P. J. Resting energy expenditure prediction in recreational athletes of 18-35 years: confirmation of Cunningham equation and an improved weight-based alternative. PLoS One, 9(10):e108460, 2014. von Hurst, P. R.; Walsh, D. C. I.; Conlon, C. A.; Ingram, M.; Kruger, R. \& Stonehouse, W. Validity and reliability of bioelectrical impedance analysis to estimate body fat percentage against air displacement plethysmography and dual-energy X-ray absorptiometry. Nutr. Diet., 73(2): 197-204, 2016.

Weaver, A. M.; Hill, A. C.; Andreacci, J. L. \& Dixon, C. B. Evaluation of hand-to-hand bioelectrical impedance analysis for estimating percent body fat in young adults. Int. J. Exerc. Sci., 2(4):254-63, 2009.

\author{
Corresponding author: \\ Klára Coufalová \\ Faculty of Physical Education and Sport \\ Charles University \\ José Martího 31 \\ 16252, Prague \\ CZECH REPUBLIC
}

Email: coufalova@ftvs.cuni.cz

Received: 26-02-2019

Accepted: 08-04-2019 